\title{
Developing a Model of Conflict in Virtual Learning Communities in the Context of a Democratic Pedagogy
}

\author{
H. Tugba Ozturk and Vivien Hodgson \\ Tugba Ozturk is a researcher in the Department of Computer and Instructional \\ Technologies Education, University of Ankara, Ankara, Turkey and Vivien Hodgson \\ is professor of networked management learning at Lancaster University Management \\ School, Lancaster, UK. Address for correspondence: Ankara University Egitim \\ Fakultesi Cebeci Ankara-Turkey; Email:tozturk@ankara.edu.tr
}

\begin{abstract}
In this paper we argue that in order to get a fuller understanding of the complexity of conflict in democratic pedagogies in online and blended learning settings, it is important to know not only how to manage or resolve it, but also how it is triggered and can be avoided. The emancipatory nature of democratic pedagogies fosters differences, and differences provide the basis for the emergence of conflict among learning community members. Much has been written on certain aspects of conflict, such as conflict management or effects of conflict; however, these studies are frequently disparate and fragmented. Conflict has a cyclical dynamic and the main purpose of this study has been to experimentally build an analytical model of this cyclical dynamic of conflict drawing on both literature and research data. We believe such a model might empower practitioners and designers of democratic pedagogies to embrace and work with the differences that lead to conflict, as a way to support collaborative learning and action. The model of conflict which emerged at the end of the study is supported by illustrative qualitative evidence and constituted in a diagrammatic depiction of analytic themes that illustrate the connections between these themes, and the values ascribed to them. The outcomes of this study have implications for developing learning strategies for distance and blended learners.
\end{abstract}

\section{Introduction}

One of the perceived advantages of working virtually in online learning groups has long been claimed to be the potential offered for more egalitarian and democratic learning conversations and communities. Yates (1997) coined the phrase 'the democratic theory' of CMC (computer mediated communication) to describe this potential. However, as Mantovani (1994) recognised, there is nothing intrinsically inherent in CMC that makes it democratic. Indeed McLaren (2015) recently suggested that ICT supported collaborative/open learning (based on CMC) has as much potential to further entrench structured inequality in learning discourse and/or learning communities as abate it. Increasingly it is acknowledged that the path to democratic pedagogy of any nature is embedded in complicated social dynamics and processes (Brookfield, 1994; Ellsworth, 1989). That conflict is inevitably present in one form or another in democratic learning communities and group work is now generally accepted. 
Within the wider critical pedagogy literature there is recognition that traditional views of democratic communities are often tainted with unrealistic assumptions about consensus and relationships. As Hodgson and Reynolds (2005) explain, in their analysis of online communities, Giroux (1992) replaced a traditional view of community with one which is characterised by 'a multiplicity of democratic practice, values and social relations' (p. 134). Fisk (1993), on the other hand, proposed the idea of a 'procedural community', where there is general acceptance of a democratic procedure that coexists with substantive conflicts.

The move towards more democratic pedagogies together with the use of collaborative groups in virtual learning communities is nonetheless seen as an important aspect and change in pedagogical thinking. Lankshear et al (1996) argued pedagogues;

"must reconfigure teaching and learning in terms of the concepts of 'links ' and 'networks' which have the power to redefine the roles of teachers, administrators and learners. Here, the notion of virtual communities holds interesting possibilities for greater democratization of education” (p. 160).

Ten years later, Arbaugh and Benbunan-Fich (2006) claimed in a review of online management education programmes it is increasingly believed that online learning communities obtain better learning outcomes when their work is structured around collaborative activities and spaces.

However there is a body of existing research on collaborative and participative virtual groups that increasingly suggests that disruptive emotions experienced while working online in virtual groups can lead to conflict and/or difficulty in making decisions which in turn can disrupt learning and prevent effective learning outcomes (Baskin, 2005; Jones, 2006; Johnson and Johnson 2009; Kellogg and Smith 2009).

Smith (2005) points out; little attention has yet been given to this emotional nature that accompanies the shift that has occurred towards more participative teaching and learning paradigms. A shift that has, as Smith explains, the underlying paradoxical tensions inherent in all group work and, she suggests, potentially even more within online collaborative group work. Applying a psychodynamic perspective Smith claims that trying to balance both the needs of the group and the individual is complex and emotion-laden. And we would add imbued with the potential for conflict. It is the nature and characteristics of the conflict found in democratic virtual learning communities and groups that this paper seeks to examine in more detail.

While there is an extensive body of literature that investigates conflict from a variety of perspectives each study tends to only focus on a selected or limited aspect of conflict. There is, we believe, no overarching conceptual framework that seeks to bring together the relevant literature supported by empirical research into one analytical and applicable model. In this paper we argue that such a model would enhance our understanding of conflict within the social learning processes of a democratic virtual learning community. 


\section{Democratic Pedagogy in Virtual Learning Communities}

Democratic and critical approaches to learning have a long history and are influenced by the work and ideas of educationalists such as John Dewey (1916), Eduard Lindeman (1926) through to the work of Paulo Freire (1972) and Henry Giroux (1983) as well as more recent radical educationist, like Elizabeth Ellsworth (1989), Robin Usher (1992), Jennifer Gore (1993) and Stephen Brookfield (1995). Now, in the digital age, revisiting democratic pedagogy in a digital learning context such as virtual learning communities (VLCs) is of increasing relevance and importance.

In this paper we thus propose to examine conflict in the context of democratic, online learning. We focus on the learning experiences of members of a Virtual Learning Community (VLC). The reason why we deal with a VLC is that the virtual learning community studied was assumed to have democratic elements as described by Schwier (2001). With regard to the democratic characteristics of a VLC, Schwier (2001) describes three aspects of virtual learning communities that contribute to and reflect their democratic potential as: elements, purposes and catalysis (p. 9). Elements of the community signify the components which bring the community members together such as mutuality, plurality, autonomy and historicity. The purposes of the community signify the different purposes of learning communities such as ideas, reflections etc. Finally, catalysis of the community signifies the events which stimulate the evolvement of the community. In this research examining the learning experiences of members of a VLC, underlined with these characteristics of a democratic pedagogy, allowed us to analyse the inherent complicated dynamics of conflict in the VLC and to develop an overarching model of conflict in online democratic virtual learning communities.

\section{Literature on Conflict}

In the paper, we focus on the literature dealing with conflict in social learning processes. In this context, the literature on conflict identifies a range of types of conflict which can be considered from both an individual and a group perspective. Conflict is an issue for the individual when his/her personal values clash with those of other community members. Also, it is important to note that the individual imports personal issues into the group, which then become an issue for the group (Smith, 2008) and consequently may lead to conflict. In this review, we have categorised conflict types discussed in the literature as either a) intrapersonal sites of conflict: an individual with his/her personal values which are in conflict with the others [i.e. 'ethnographic characteristics' such as a priori experience-knowledge, working preferences, wishes and interest (Ayoko et al, 2002; Ference \& Vockell, 1994; Huang, 2002; Johnson \& Johnson, 2009; Ke \& Chellman, 2006; Morgan et al., 1998)] or b) interpersonal sites of conflict explicitly emerging during social interactions [conflict in power relationships (Blasé, 1991; Wenger; 1998) and in argument/counterargument (Stegmann et al., 2007)]. This categorization is helpful in examining conflict from the perspective of an individual (intrapersonal conflict) as well as the conflict which is generated during community members' interactions (interpersonal conflict) (See Figure 1).

It is often claimed that conflict emerges from incompatible differences (Johnson \& Johnson, 2009). However pre-existing differences are often regarded in democratic pedagogy as an important source for enhancing learning. Schwier (2001) suggests that in the context of VLCs, plurality signifies different points of view and diversities in 
VLCs; from them, learning experiences of the members may gain vitality and richness. From this perspective, it is understood that differences do not necessarily lead to conflict between individual, group and community. In this sense, to learn more about what makes the issue of differences a matter for conflict is important.

\section{Conflict in learning groups}

As Gore (1999) explains in a learning group in which democratic pedagogy is adopted, it is assumed important for students to articulate their different points of view and learn through negotiation. Further, Stegmann et al (2007) points out that conflict that arises in argument and counterargument can be resolved when these two arguments are integrated in a way that defines "a new perspective in which the main claims can be sustained in a logically consistent and coherent way" (p. 432). From this perspective conflict emerging from the articulation of different points of views is potentially an important dynamic in democratic pedagogy especially where the dialectical emergence of conflict between argument and counterargument prepares the ground for the social construction of knowledge.

On the other hand, when not resolved, conflict can impede the progress of collective work. As researchers point out, conflicts faced in the learning process can end up reducing group effectiveness and in an impasse, undermining the group's cohesiveness (Griffiths et al., 2005; Kuhn \& Poole, 2000; Passos \& Caetano, 2005).

When considering conflict as a dynamic group process, it is also important to consider the potential for an imbalance in power relations leading to a situation of oppressive authority and conformism. This in turn can lead some learners to become passive members of the community. Hodgson and Reynolds (2005) for example refer to a learning community's limitations in relation to accommodating differences and the oppressive aspects of conformity, leading to obstacles or constraints on participation for some learners. In the case of conformism to dominant power, individuals can be repressed (Whitworth, 2005) and might comply with the mandates of others making some types of conflict hidden or latent to others in the group.

A further point from previous studies concerns the size of a group in regard to conflict. According to these studies, as group size increases, the heterogeneity of the group requires a different level of effort and action and this in turn may trigger emergence of conflict. In these studies the relationship between group size and collaborative elements such as communication, coordination, trust, competition and group effectiveness were all found to be possible influences on the occurrence of conflict (Kollock, 1998; Hjertø, 2006; Gabriel and Griffiths, 2008). When conflict emerges, Staggers et al (2008) and Thomas (1992) refer to issues related to the resolution of conflict and comment that over time students often tend to develop a conflict management style such as accommodating, avoiding, competition, collaboration, compromise and forcing.

\section{Conflict in online learning groups}

Previous research suggests that heterogeneity of the groups in global learning (Paul et al, 2004; Correia, 2008) and diversifying demographic characteristics of students and differences among students (Hinds \& Mortensen, 2005; Hodgson \& Reynolds, 2005; Xie et al, 2013) can all be regarded as potential sources of conflict. Conflict is cited 
as a challenge in geographically dispersed group studies (Picard, 2006; Xie et al, 2013) and in cross-cultural studies (Weinberger et al, 2013).

In regard to the characteristics or conditions of inherent conflict in online learning, Benbunan-Fich and Hiltz (1999) suggest that, in asynchronous collaborative learning settings if the participants are not present at the same time and place while coordinating the group work, then conflicts are very likely to emerge. This is reminiscent of Hinds and Mortensen (2005) finding that in distributed work teams' spontaneous communication, meaning the informal, unplanned interactions that occur among team members, is "associated with a stronger shared identity and more shared context"; Hinds and Mortensen claim that this kind of spontaneous communication mitigates conflict in distributed virtual work teams (p. 290-291).

Further grounds for anticipating the presence and experience of conflict in online settings could be summarized as the properties of these settings to foster anonymity and depersonalize relationships (Zornoza et al., 2002). According to this view, in online settings, it is likely that the users focus intensely on the task rather than paying attention to interpersonal relationships, which in turn avoids emergence of conflict.

To sum up, in general, in technologically supported social learning environments, there has been little formal research that deals with conflict and its dynamics. Further, few research studies focus on conflict in social learning processes, based upon democratic pedagogies. In the current study we sought to examine conflict in the context of online learning by focusing on learning experiences of members of a Virtual Learning Community (VLC). The design of the virtual learning community in question was intended to support democratic learning values and characteristics.

The study reported in this paper focused specifically on the following research questions in the context of a Virtual Learning Community (VLC):

(1) What is the internal dynamic of conflict that turns pre-existing differences to become a matter of conflict?

a. What triggers the conflict?

b. How is the conflict avoided?

(2) What types of conflict are experienced in virtual learning communities?

(3) What is the result of these conflicts?

(4) What is the role of conflict in the social learning process?

\section{Research Site and Design}

The research site chosen was a course from an ongoing third-year undergraduate programme titled Computer and Instructional Technologies Education in Turkey. The research was conducted in two stages: 1) pilot study and 2) main study in a course titled "Distance Education" during two academic terms in 2008 (pilot study lasting 4 weeks) and in 2009 (main study lasting 14 weeks). The educational aim of the course was to gain knowledge about distance education practices. Before the course began, the tutor, an experienced facilitator, and researcher designed the course in such a way that it was intended by the end students would find solutions to distance education problems through a project identified and managed by them. In the scope of this course, 33 students were randomly divided into 5 groups and worked together both in 
face-to-face (FTF) and online settings (on Moodle). On Moodle, discussion forums, wikis and synchronous communication tools were used.

The intended aim was to achieve the design of a community in which learners pursue their own individual goals. In the first 3 weeks the students were introduced to the idea of Virtual Learning Communities as well as basic knowledge about how the course was taught. After the third week of the course, students were invited to continue the course, according to their own preferences and interests. The students were able to discuss the course content as well as their wishes on how to administer the course on Moodle. The content was loosely structured. It was envisaged in the design that the tutor would not be at the centre of the learning network, but would be a co-learner.

The aims and curriculum of the Distance Education course were considered appropriate and in line with democratic values and principles. Each learning group was responsible for producing at the end of the course a report on a subject matter of interest to them about Distance Education and for presenting their project findings to the other students. At the end of the course, the students chose to develop projects with regard to training illiterate people living in rural and isolated areas through instructional radio programmes. Their projects thus gave the students an opportunity to work for others in society, to improve disadvantaged groups' lives. By including this experience and activity it was assumed that the students' social sensitiveness in how their acquired knowledge on the course could be applied in the field of literacy would be honed. This in turn could be considered a building block for developing understanding of the position of self and others more widely in society.

\section{Methodology}

The study of the course was based on a grounded theory methodology according to which 'discovered' reality is produced through the interactive process between researcher and subjects; and the aim is to report interpretive renderings of reality (Charmaz, 2010). In accordance with this qualitative research inquiry, we adopted an interpretive approach to conflict, in line with the orientation of this research. The steps in the coding process and construct development are described below.

\section{Data Sources}

Altogether 33 students and one tutor participated in the research. Table 1 summarises the research sample and data source used in the study. 
Table 1: Data sources

\begin{tabular}{|c|c|}
\hline Data sources & Description \\
\hline \multicolumn{2}{|l|}{ A. Data Collection Tools } \\
\hline $\begin{array}{l}\text { Pre-course questionnaire questions } \\
\end{array}$ & 29 students returned the questionnaires. \\
\hline $\begin{array}{l}\text { An essay of a member who wants to } \\
\text { change his group }\end{array}$ & $\begin{array}{l}1 \text { student requested to change his group and stated this with an } \\
\text { essay (email). }\end{array}$ \\
\hline $\begin{array}{l}\text { An essay of a member who wants to drop } \\
\text { the course }\end{array}$ & 1 student wanted to quit her group work and drop the course. \\
\hline Interviews with the tutor & $\begin{array}{l}\text { One after the first session. } \\
\text { Second after the focus group with students }\end{array}$ \\
\hline $\begin{array}{l}\text { Focus group meetings at the end of the } \\
\text { study }\end{array}$ & $\begin{array}{l}28 \text { students participated in the focus group meetings. Post- } \\
\text { course focus groups were conducted in } 2 \text { groups. First group } \\
\text { consists of } 15 \text { students + second group consists of } 13 \text { students.) }\end{array}$ \\
\hline Post-course questionnaire questions & 33 students returned the questionnaires. \\
\hline \multicolumn{2}{|l|}{ B. Learning Environments } \\
\hline $\begin{array}{l}\text { Moodle and a Web Based Learning } \\
\text { Environment }\end{array}$ & $\begin{array}{l}\text { - Asynchronous communication } \\
\text { - Synchronous communication } \\
\text { - Moodle logs and reports } \\
\text { - Project reports, presentations (power point) }\end{array}$ \\
\hline \multicolumn{2}{|l|}{ C. Other } \\
\hline Summaries of emails from students & \\
\hline
\end{tabular}

There were 33 students taking the courses of which 7 were female and the remaining 26 male. All the students were in the age range of $20-27$ with the majority under 23. A form was provided on Moodle for the students who wanted to change their group or drop the course. This form was available for them throughout the course and was aimed at finding out the reasons why a student wanted to change his/her group or drop the course, and to what extent conflict could have played a role in his/her request.

The two focus groups were conducted essentially to explore the interpersonal site of conflict. In the focus group meetings, the aim was to capture interaction among students, and heated discussions emerged from this social interaction, which in turn enabled us to examine closer interpersonal sites of conflict.

In addition, pre \& post-course questionnaires were used in order to collect data about intrapersonal sites of conflict by addressing individual questions. The pre-course questionnaire was used to bring to the surface existing conflict-related characteristics of group members, such as expectations, aims and prior knowledge of other members. 29 of 33 students returned their questionnaires. In the post-course questionnaire, questions which were similar to those in the pre-course questionnaire were addressed, but conflict which the students experienced during the course was explicitly asked about. 33 students returned the post-course questionnaires. The changes in students' answers in pre- and post-course questionnaires were helpful in indicating conflict which emerged during the duration of the course. Finally, as a member of the VLC, the tutor of the course was also interviewed before and after the course.

In the remainder of this paper participants are coded by using the pseudonym of "Subject 1, 2, 3, etc" to protect their anonymity and to avoid tracing their identity in the data.

\section{Data Analysis}

Qualitative data analysis was used in this research. The coding process was informed by constructivist grounded theory and included the following stages as suggested by 
Charmaz (2010): 1) Line by line coding, 2) Constant comparison (Comparing different people, data sets, incident by incident, data with category and a category with other categories) (p. 188).

In the research, in terms of construct validity, literature was utilised in order to provide consistency between the concepts, while interpreting the data and the concepts of well-established knowledge in the field based on the literature. The initial coding schema was developed from the literature and included conflict concepts found in the data. However in developing the coding scheme, whenever any literature based concepts of conflict were not found in the data these were removed from the coding scheme. On the other hand emerging conflict-related concepts found in the data were added into the coding schema. Appendix 1 shows a copy of the coding scheme based on both the literature and data. The emerging concepts in the data were thus following Dey (2007) well-founded, both empirically and conceptually.

Further, during focus group meetings conducted at the end of the field work, the student members were asked some validation questions. These questions concerned the validity of the observations in the field (whether the observations about them and the field in general were accurate from their point of view).

The themes emerged from the data as a result of this coding process and the analysis aimed to produce an account of the connections that were made between the themes, and the values ascribed to them. The results of the analysis is summarised in a diagrammatic depiction of analytic themes (Figure 1). In the analysis process, data were dealt with at individual and group level, and community level (whole educational actors in the community), including all roles in the community (e.g. tutor and students).

\section{Developing a Model of Conflict}

Figure 1 summarises the emergent model of conflict and describes the typology of conflict which we now discuss in the remainder of the paper: 


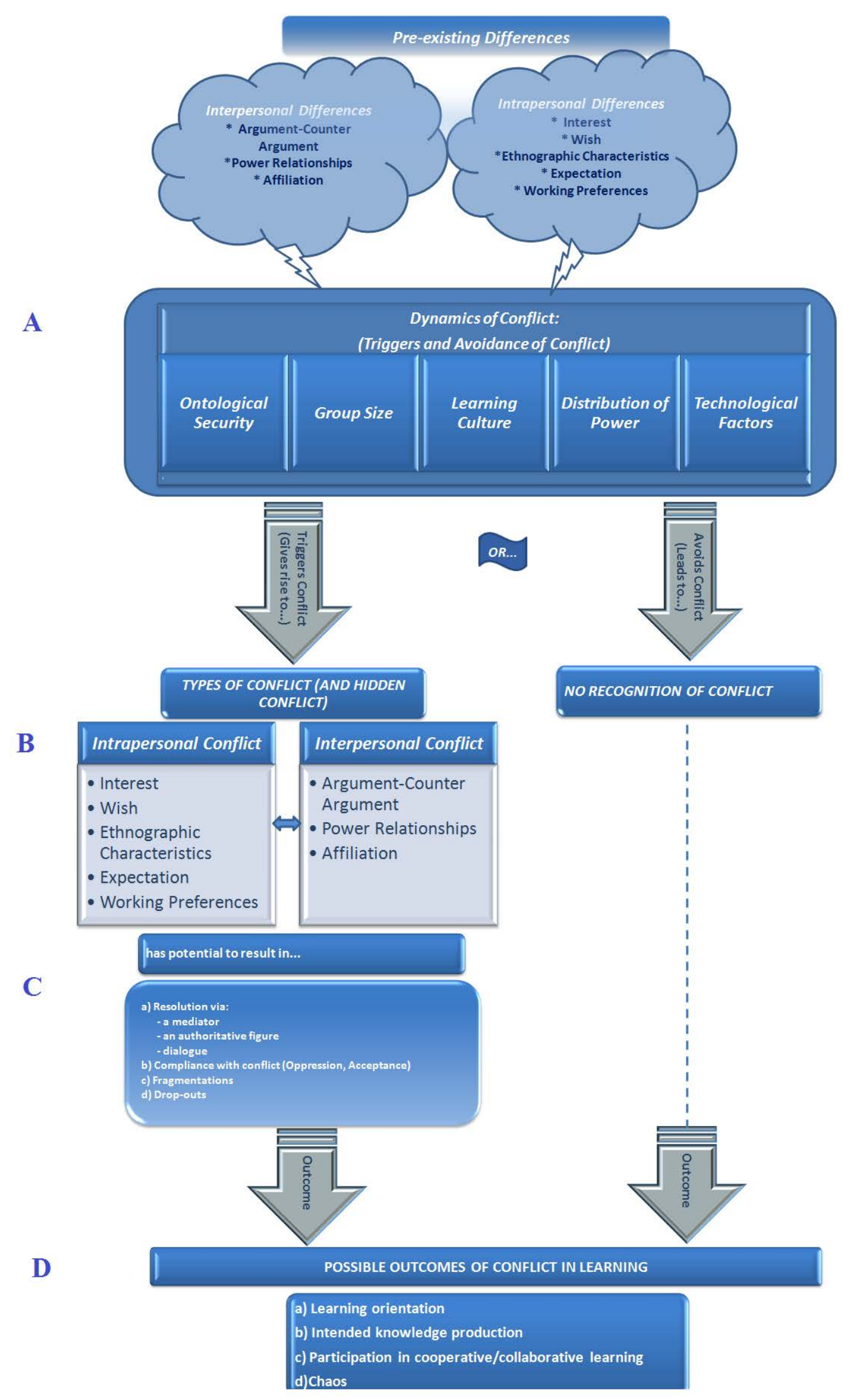

Figure 1: Model of conflict in the social learning process 


\section{Pre-existing differences}

In order to explore individual characteristics of the community, members' demographic and potential conflict-related information was gathered via the precourse questionnaire. The findings enabled us to review members' prior existing conditions (e.g. prior knowledge, expectation, and working preferences) which later on might have the potential to lead to conflict in the learning process. As well as allowing us to see whether these differences are triggered and perceived as conflict or are avoided and not perceived as conflict among VLC members.

However, it is important to note that some of these individual properties may have changed during the course (e.g. aims and expectations of the students may have changed) while others remain substantially the same across the whole learning process (e.g. ethnographic characteristics and working preference). Therefore, we only present a general overview of the community members as an example to illustrate the kinds of pre-existing differences. The table in Appendix 2 demonstrates the findings based on the pre-course questionnaires. 29 student members returned the pre-course questionnaires; however, in this table Total values represent the number of total answers given to the questions in the specified category, and $N$ (frequencies) represents the number of answers given to each individual question within this category. For some questions, student members ticked more than one option and therefore, in some categories the number of the Total answers may be more than the number of student members returning post-course questionnaires.

The responses to the questionnaire questions were recorded for individual students and at this stage of analysis, the findings were left open for further investigation in the deeper analysis of conflict in the next stages of the research. In order to briefly present the overall picture of conflict characteristics of the student members, some highlights of the findings shown in Appendix 2 are summarised below:

- Almost half of the members (46.66\%) shared the same aim towards the course, which was to learn about distance education practices and theories.

- Many of the students (66.6\%) described their prior knowledge as having some understanding of the subject.

- The majority of the members (84\%) described themselves as self-motivated learners.

- Almost half of the students (42.83\%) usually look for tutor guidance in their courses to learn the subject.

- A large proportion of the students (57.17\%) usually prefer to work without any interference (e.g. work independently without any interference of a group mate or tutor).

- The majority of the students (61.29\%) prefer to work individually.

Thus it appeared most of the students claimed to prefer not to work in groups but to work individually and relatively few preferred to take the lead role. Most students suggested they preferred working democratically or equally. There was however an interesting split between those students who responded that they preferred to work without interference as opposed to those who preferred being led by the tutor. Also a third of students said they had little prior understanding of the subject. This potentially put those students at a disadvantage and with a different predisposition towards the course to the rest of the students; who claimed to have prior knowledge or 
understanding of distance education. The greatest variation amongst the students appeared to be in their responses to the questions on expectations about educational approaches and methods used, while learning about distance education or getting a good grade were the main aims identified by the students.

\section{A. Exploring the Internal Dynamics of conflict (a. Trigger b. Avoidance)}

The first part of the model (A) describes influences identified in the research that were found to trigger conflict or alternatively lead to the avoidance of conflict. In the literature, group size and learning culture were identified as potential triggers or characteristics that led to avoidance of conflict. These dynamics were also seen in the data. Although technological factors as a dynamic of conflict have been identified in the literature, in this research in order to reflect on democratic pedagogy in technology supported learning settings, we will present examples of student experiences in regard to conflict resulting from technology. In the data, two additional factors, ontological security and distribution of power, were identified as dynamics of conflict as we will discuss further below.

Ontological security Ontological security refers to the existential feelings of an individual in relation to his/her experiences concerning a sense of social order and continuity (Giddens, 1991). In line with McConnell's (2005) research, partially dealing with ontological security in collaborative e-learning groups, in this study students talked about being 'happy' and 'anxious' as well as 'trusting' others. As an example, in the pilot study a student who experienced conflict with her group mates stated in her essay: "I did not trust them and I never felt I belonged to the group". At the beginning of her group work, this student joined the group discussions to work collaboratively with her group mates in the virtual learning setting. However, when her group mates were fulfilling their task, she experienced conflict and left her group. Her group experience demonstrated that she initially tried to participate in group work; however, she did not trust her group mates or have a sense of ontological security within the group. Her lack of ontological security triggered her pre-existing differences with the group and led to the emergence of interpersonal conflict. In the sense that Lack of 'trust' and 'differences' fed off each other, and this triggered the conflict. Here, the nature of blended learning also takes an important place in understanding conflict in online settings; the student suddenly left the online environment and quitted the group work. At first sight, by considering her nonpresence in the online setting, the tutor and her fellow students might think that she quitted her group work due to her unwillingness to perform her task, as there is no other evidence in an on online setting. However, in fact her non-presence is related to the conflict and her personal contact with her friends in their face to face courses. In the scope of VLCs, Schwier (2001) refers to the 'historicity' aspect of a VLC which refers to past, present and future of the members in a life cycle of a community. A VLC is a living community and in order to make members' engagement more | meaningful, their ontological security related feelings should be taken into account.

Distribution of power Distribution of power (holding the a/symmetrical power to administer the process, resources, persons etc.) has the potential to either trigger or avoid conflict. In democratic virtual learning communities members are frequently assumed not to have more powerful positions than others as a result of their roles in the community. However, as revealed in this study, sustaining an equal distribution of power among the members of a VLE is not always realistic (e.g. students often chose 
a leader by their own free will which then instigates conflict in power relations with the leader). Any asymmetrical distribution of power can lead to conflict. While having a leader in a group can be effective in ending conflict (Gabriel \& Griffiths, 2008) in didactic learning environments, in democratic pedagogies, after setting up the ground rules based on equality, unequal distribution of power is more likely than not to lead to conflict among community members.

On the other hand, distribution of power can also play a role in the avoidance of conflict. On Moodle (under the General Discussions thread), students demanded postponement of the course for a week, because the timing of the course coincided with the week of a bank holiday, and students wished to take this week off. The discussions were started off by one student and then spread to the other community members. As the majority of the members wanted to cancel the course, their power to put this into effect, combined with the tutor`s willingness (as a member of the community where his decision is equally important to that of the students) to accept or reject their demand, signified distribution of the power to administer the learning process. The equal distribution of power was shared among the educational actors in accordance with democratic pedagogy and avoided conflict. This gives us a sense that when there is no clear authoritative figure, unless a demand of a member is considered by all members, conflict which leads to drop outs or puts the members off the course can be avoided.

Technological factors It was revealed in this research that when technology functions as a way of facilitating communication among the members or, on the contrary, impeding communication, generally for technical reasons, it plays a role in the emergence of conflict by either triggering or avoiding conflict. For instance, in the main study, Subject 3 was faced with a technological difficulty and could not locate where his group mates were discussing their topics on Moodle. He posted his arguments under a different thread from the one he should have done. This impeded his participation in the group work and therefore communication with other group members. This resulted in conflict with his group mates, as they misinterpreted his nonparticipation, thinking that his nonparticipation was arbitrary and that he was not interested in their group work. Possibly drawing on his experience with conflict with his friends and the role of technology in experiencing this, in the focus group meeting, Subject 3 remarked that the internet individualizes the learning process and in his case, technology had not helped in promoting dialogue.

On the other hand, by providing a communication medium, technology can facilitate dialogue among members and thus avoid the possible emergence of conflict. For instance, in the post-course questionnaire, Subject 15 referred to how technology had brought together the learners who had previously been dispersed and helped them reach their goals by working together. He stated: "Coming together with the individuals from different locations and sharing knowledge was very fruitful and made a difference".

A further point concerns the way students showed their emotions in online settings, prior to being faced with conflict. In virtual settings, as a way of communication, body language was replaced by emoticons. In the context of conflict, it was observed that emoticons were frequently used when the differences which provide a base for conflict were seen. 


\section{B. Conflict Types}

The next part of the model (B) looks at conflict types. All the conflict types identified in the literature (argument and counterargument, power relationships, interest, wish, ethnographic characteristics, working preference) were found in the data. However, other conflict types such as conflict in affiliation and expectation emerged. Conflict in affiliation, refers to a person's lack of identification with the group, and emerged as an interpersonal type of conflict. In the focus group meeting, a group member said: "In the other group of which I was a member, I stumbled. It is because in the group work [which was going to be assessed as a group study], it is not clear whether you are actually an individual or a part of a group. To some extent, you are a part of the group as an individual, but when you are in the group individually, it does not make sense to call this `a group.”

In terms of intrapersonal conflict, in the pilot study a new conflict type emerged between the tutor and students which was identified as conflict in expectation. Accordingly, the students' expectations of the tutor were different from those of the tutor. This became a matter of concern for students, because their learning experience was impeded, as they could not or did not want to meet his expectations. The students expected a more didactic course and asked the tutor to accordingly make some adjustments to provide more didactic arrangements. However, according to the democratic learning values such as sharing responsibility of learning among all educational actors and a learning process which is based on students' preferences and interest, the tutor expected students to manage their own learning process without the intervention of any authoritarian power and this in turn led to the emergence of conflict in expectations. In that the democratic learning values and expectations embedded in the course design used and adopted by the tutor in the course were frequently different to that of students who expected or wanted a more didactic approach.

\section{Potential results of conflict}

Part $\mathrm{C}$ of the model examines the potential results of conflict. Throughout the field work, the aim was to capture relationships as well as historical sequences in experiencing conflict, which in turn demonstrated how the conflict types/dynamics influenced learning experiences of the members, as seen in Figure 1.

Briefly, it was observed that some of the instances of conflict followed a pattern of historical sequences and with varying tendencies (e.g. students and groups could follow a different pathway in the model. For instance, while members of Group 1 indicated accommodating learning culture as a conflict dynamic and did not perceive any conflict, members of Group 4 exhibited a different pathway of conflict and they were influenced by large group size and technological factors as conflict dynamics; as a result, they experienced severe conflict). It is important to note that, as the name implies, the dynamics of the conflict consist of changeable situations, and Figure 1 is more about a snapshot of conflict instances which surfaced in the data. The aim is not to assert that the flow of the elements of conflict is the same for all situations during the life cycle of a community. As a concrete example, Subject 15 mentioned the changeable flow of the conflict that he experienced in his group work: "Sometimes, there were disagreements in the group about having the same goal and expectation. Because of this, we were aware of different expectations and worked more comprehensively. And this contributed richness to the educational process.” 
As a result of conflict dynamics, if conflict avoidance occurs, then the community members must live with the differences and do not perceive these differences as a matter of conflict (No recognition of conflict). If conflict is triggered and emerges, then the scenario has two possible outcomes: conflict is resolved or conflict remains unresolved.

In line with the literature, in this study, reaching consensus, or in other words conflict resolution, is one of these situations. Briefly, data showed that conflict can be resolved via a) a mediator b) an authoritative figure c) dialogue. Among these situations, conflict resolution via a mediator and dialogue which were identified in the literature (e.g. Smith, 1997) were also captured in this research. In addition, in the field work, it was noticed that the authoritative figure of the tutor was influential in resolving conflict. As an example of this, while learning groups were choosing their topics to work on, there was an incident in which two groups took the same topic on Moodle (under the task allocation thread). One member of the two groups (Subject 10) used a tutor's name as an authoritative figure to influence the result of the conflict to her group's advantage. She wrote on Moodle that: "Subject 13 [her group mate] informed [the (guest) tutor] that we have already chosen this topic". In the context of a democratic pedagogy, authority of a tutor is intended to lie only in his or her moderator role. In line with this, in an attempt to resolve the conflict between the students, the tutor reminded the students of the rules in place were ("first come first serve") in choosing the topic. The tutor declared who actually chose the topic first based on the Moodle logs and this ended the conflict.

A further situation that was captured in the data was seen when conflict was not resolved. In situations in which conflict is not resolved, the following are possible: a) community members may comply with the conflict (oppression or acceptance) b) fragmentations may emerge and c) drop-outs may occur.

Among these situations, compliance was discussed in the literature section. In this study, a group of students could neither resolve the conflict nor comply with it, and as a result of this, fragmentations (e.g. subgroups) emerged. As an example of this, Subject 21 referred to the conflict they experienced and how it resulted. He said: "While allocating the tasks, some different sub-groups emerged. However, we reconciled in the end."

The final situation is one in which a 'drop out takes place in the learning process if conflict intensifies, but cannot be resolved. In the field work, a student dropped out of the course, because of the severe conflict that she was experiencing with her group mates.

A further point is that all of these situations tend to influence the members' learning experience in various ways, which is discussed in the next section.

\section{Influence of conflict in learning (Outcomes of Conflict)}

In this research it was found that, depending on the different types and results of conflict, the learning experience of the group members tended to be influenced in one or more of four different ways: Learning orientation, intended knowledge production, participation in cooperative/collaborative learning and chaos. Although these 
learning situations can be considered as interconnected, for some community members the conflict they encountered meant they were likely to experience some of these learning situations more than others.

\section{Learning orientation}

Learning orientation signifies an individual's desire, belief and interest in learning. Below is an extract from the data as an example of learning orientation when conflict was experienced.

In the post-course questionnaire, Subject 10 referred to her learning orientation when she experienced intrapersonal conflict (conflict in interest), saying: "[...] whilst I was working on my topic with a high level of attention and wanted to improve myself, my friend in the same group was okay to risk not even attending the class on the day of our presentation. And that, perhaps to some extent, was putting me off the group”.

Her interest in the course required a considerable amount of work (as she said, it was necessary to pay a high level of attention in the course or exert a lot of effort to improve oneself etc.). However, she experienced conflict with a member in her group as this member did not have the same interest as she had; as a result of this conflict in interest, she lost her prior orientation towards the group work and lost her desire to work with the same member(s)

Intended knowledge production

Intended knowledge production refers to the process in which community members actively work together on social knowledge construction.

Drawing on the data, it was observed that when group members did not necessarily recognize or acknowledge conflict, depending on the nature of the conflict type present this could nonetheless lead to productive learning outcomes. For instance, in the field work, most of the Group 1 members (4 out of 6 ) did not recognize any intrapersonal conflict in their learning process (e.g. in her post-course questionnaire, Subject 5 in this group said: "There were many things in common. Differences did not influence [us] very much"). So, how does non-perception of conflict play a role in their learning? On examining the group's report submitted at the end of the group work it was seen that the group report consists of coherent sections: sub topics are handled with almost the same dimensions and findings were consistent throughout the report. This all suggests that the group worked productively to get this result and through the avoidance of conflict were able to allocate more time on intended knowledge production and to all intents and purposed present a coherent outcome at the end of their group work. However, it is important to note that non-perception of conflict does not necessarily lead to high quality outcomes. No recognition or avoidance of conflict is not always a good thing and can lead to inferior quality outcomes to those produced when conflict is acknowledged and actively worked with.

For example if conflict derived from power relationships is avoided and ends in favour of those who are perceived to have greater authority/power, this can dominate the experience of the learning process, leaving others passively accepting the dominant member's interpretation. In the final outcome, the ideas, thoughts and knowledge of the powerful members can be widely observed in the work of the group, while the 'oppressed' group members passively accept the dominant side's version of 
knowledge. In the field work, one of the groups' (Group 2) asynchronous discussions, which took place on Moodle, is a good illustration of this. In their asynchronous discussions, a group member dominated the group work and experienced conflict with another member in his group. This conflict resulted in the dominant student 'winning'. After reviewing the end product of this group work (a power point presentation), the strong influence of this group member's ideas on the presentation was obvious.

A further example of the influence of conflict on intended knowledge production can be seen in conflict in arguments. In the focus group meeting, Subject 25 referred to conflicts in argument and counterargument and said: "[...] This might have reflected positively on [our] learning, because the emergence of different ideas, while it may lengthen the process, in the end is important for learning”. Thus, as happened in this example, recognised experienced conflict resulted in productive learning outcomes for the members.

\section{Participation in collaborative or cooperative learning}

Dillenbourg (1999) differentiates between collaborative and cooperative learning as: "In cooperation, partners split the work, solve sub-tasks individually and then assemble the partial results into the final output. In collaboration, partners do the work 'together "; "Collaborative activity requires more than the effective division of labour that constitutes cooperative work" (p. 11; 21).

In a practical sense, this differentiation is important when conflict is experienced, as members either tend to produce more individual work as they work cooperatively, or on the other hand, more collective work as they work collaboratively, depending on the conflict they experience, whereas collectivism is assumed integral for democratic pedagogies. As an example, in the field work, members of Group 3 experienced intrapersonal conflict and this led them to individualize the learning process, thereby giving full expression to individual differences (individual differences which result in intrapersonal conflict). So, rather than embracing the differences they possess and working collaboratively, they preferred to divide the group task into individual tasks and worked cooperatively. Consequently, the end product changed and more individual values were seen in the outcome of the group work, highlighting a situation of conflict and its role in learning. In other words, some group members changed their way of working from collaborative learning to co-operative learning as a way to resolve the conflict problem.

\section{Chaos}

Chaos signifies lack of order which emerges through uncertainty or lack of clarity. If conflict is not resolved, it may subsequently result in chaotic situations for the students. For instance, during the field work, the tutor and learning designer experienced conflict over the decision about what to do when an unforeseen situation happens. As they were unable to reach consensus, this became reflected in the students' learning experience in the way they faced chaotic uncertainty, regarding what to do in their course, and for a period of time they felt anxious about their success in the course.

However, in the context of democratic pedagogy which is based upon negotiations between two or more parties on different sides, it is important to remember Gramsci's 
point as every crisis is also a moment of reconstruction and an opportunity for change (Kahn and Kellner, 2007). Therefore, chaos should be regarded as a natural process which could result in new learning situations (reconstruction).

\section{Summary and Conclusions}

This article has attempted to contribute an update to the extant literature on conflict in social learning processes by investigating a key challenge in democratic pedagogies, which is conflict in the context of virtual learning communities. Through this research the aim was to raise the awareness of conflict for designers and practitioners of democratic pedagogies by presenting a practical and comprehensive model of conflict. The developed model includes types, dynamics, results and roles of conflict in a social learning process.

The conflict types described in the model are important in recognising conflict in a learning programme. Knowing the different conflict types can help guide practitioners in their democratic teaching praxis. The internal dynamics of conflict to some extent refer to the conditions in which community members experience their learning. In that sense, the dynamics of conflict have a significant place in assuring optimum learning outcomes for the learners (e.g. group size could be small and a facilitator in an online learning environment could take a role in fostering an accommodating learning culture).

Once conflict emerges, it leads to variations in the influences on community members' learning experiences. In the model these variations are categorised as 1) learning orientation 2) intended knowledge production 3) participation in collaborative/cooperative learning 4) chaos. Although outcomes of conflict appear to be connected and inseparable in this study, the community members tended to experience one or other more intensely.

The above analysis suggests that it is important to try to follow the flow of the conflict through the learning process and to see and be aware of the whole picture emerging in a learning communities' experience of conflict.

Implications of the study

The model of conflict described in this paper could allow practitioners to introduce the concept of conflict to their students at the beginning of their course. This is important because as in this study, it is generally not the students demanding democratic pedagogical approaches. It is generally us as educators who influence the course design in virtual learning environments to be in line with democratic learning. However, as in this study if students have not come from a learning background where they are familiar with emancipated or democratic learning and the potential for conflict occurring it is important to introduce them to this dynamic in particular the potential for conflict with the tutor who insists on democratic learning and students who expect or request didactic learning. In the same vein, conflict emerges amongst learners because they lack awareness of a learning culture based on dialogue and negotiation whereas aspects such as critical dialogue promote diverse students to engage in discussions (Parker, 2013). Therefore, at the beginning of a course, introducing the idea of conflict through a model like the one developed in this study to the learners could help them to be more aware of the complexity of group learning 
experiences including the potential, as identified in the model, in online setting, about the impacts of technology in experiencing conflict.

A further implication of the study concerns the influence of online learning environments and their communication specificities in the generation, evolution and resolution of conflicts. A body of literature indicates that many teachers do not feel confident utilising open dialogue about conflictual issues (Parker, 2013). In online settings, it is even harder to design and run a course with democratic values. Practitioners must be aware of the likely misunderstandings in a VLC due to the different kinds of access to information and communication patterns to those available and experienced in face-to-face settings. They should not only pay attention to the quality of the students' postings but also be alert to their use of the allocated designated spaces in a virtual learning environment and the potential for conflict to occur

Another point concerns the design of the course researched. A blended learning approach was used and as the students already knew each other, there were no icebreaking and trust-building activities included at the beginning on Moodle. The students were only expected to articulate their expectations for the course as part of an activity to get familiar with the use of Moodle. However aspects such as a trust building activities in virtual environments are very important for VLC members to feel a part of a "community" as well as for taking advantage of online environments for both managing and learning from conflict when it occurs.

In conclusion, the model of conflict developed in this paper offers a more holistic and dynamic understanding of conflict within the social learning processes of a democratic virtual learning community. It emphasises the organic connection to key democratic processes such as consensus, dialogue, compliance and knowledge construction. Further, the model and the results of this research reinforce the view that conflict is a present and normal dynamic in democratic online pedagogies that contributes to learning. It is thus better to acknowledge and introduce students to the expectation of conflict than to ignore or supress its presence.

Acknowledgments

We would like to acknowledge the valuable insights and contribution of Mary Hamilton and Gale Parchoma during the earlier empirical research study on which this paper is based. We would also like to thank the BJET journal reviewers for their constructive and helpful feedback during the review process.

\section{References}

Arbaugh, J. B., \& Benbunan-Fich, R. (2006). An Investigation of Epistemological and Social Dimensions of Teaching in Online Learning Environments. Academy of Management Learning \& Education, 5(4), 435-447.

Ayoko, O. B., Härtel, C. E. J., \& Callan, V. J. (2002). Resolving the puzzle of productive and destructive conflict in culturally heterogeneous workgroups: a communication accommodation theory approach. International Journal of Conflict Management, 13(2): 165-196.

Baskin, C., Barker, M., \& Woods, P. (2005). When group work leaves the classroom does group skills development also go out the window? British Journal of Educational Technology, 36 (1), 19-31. 
Benbunan-Fich, R., \& Hiltz, S. R. (1999). Impacts of asynchronous learning networks on individual and group problem solving: A Weld experiment. Group Decision and Negotiation, 8, 409-426.

Blasé, J. (1991). The Politics of Life in Schools: Power, Conflict, and Cooperation. Newbury Park, Calif. : Sage.

Brookfield S. (1995). Becoming a Critically Reflective Teacher. San Francisco: Jossey-Bass.

Brookfield S. (1994). Tales from the dark side: a phenomenography of adult critical reflection. International Journal of Lifelong Education, 13 (3), 203-16.

Charmaz, K. (2010). Grounded Theory: Objectivist and Constructivist Methods. In W. Luttrell (Ed.) Qualitative Educational Research. Readings in Reflexive Methodology and Transformative Practice (pp. 183 - 207). New York and London: Routledge.

Dey, I. (2007). Grounding categories. In A. Bryant and K. Charmaz (Eds.) The Sage Handbook of Grounded Theory (pp. 167-190). Los Angeles, Calif.: Sage.

Dewey, J. (1916). Democracy and Education. MacMillan, New York.

Correia, A-P. (2008). Team conflict in ICT-rich environments: Roles of technologies in conflict management. British Journal of Educational Technology, 39 (1), 18-35.

Dillenbourg, P. (1999). Collaborative Learning. Cognitive and Computational Approaches. Amsterdam ; New York : Pergamon.

Ellsworth, E. (1989). Why Doesn't This Feel Empowering: Working Through the Repressive Myths of Critical Pedagogy. Harvard Educational Review, 59(3), 297324.

Ference, P. R., \& Vockell, E.L. (1994). Adult Learning Characteristics and Effective Software Instruction, Educational Technology, 34, 25-31.

Fisk, M. (1993). Community and morality. The Review of Politics, 55, 593-616.

Freire, P. (1972). Pedagogy of the Oppressed. Penguin Books, Harmondsworth, Middlesex.

Gabriel, Y., \& Griffiths, D. S. (2008). International Learning Groups: Synergies and Dysfunctions. Management Learning, 39 (5), 503-518.

Giddens, A. (1991). Modernity and self-identity: self and society in the late modern age. Cambridge: Polity Press.

Giroux, H. (1983). Theory and Resistance in Education. London: Heinemann Education Books.

Giroux, H. A. (1992) Border crossings: cultural workers and the politics of education. New York: Routledge.

Gore, J. M. (1993). The Struggles for Pedagogies. New York: Routledge

Gore, J. M. (1999). On the limits to empowerment through critical and feminist pedagogies. In D. Carlson, \& M. W. Apple (Eds). Power/Knowledge/Pedagogy: The Meaning of Democratic Education in Unsettling Times (pp. 271 - 288). Boulder, CO: Westview Press.

Griffiths D. S., Winstanley D., \& Gabriel Y. (2005). Learning shock: The trauma of return to formal learning. Management Learning, 36(3), 275-297.

Hinds, P. J., \& Mortensen, M. (2005). Understanding Conflict in Geographically Distributed Teams: The Moderating Effects of Shared Identity, Shared Context, and Spontaneous Communication. Organization Science, 16 (3), 290-307.

Hjertø, K. B. (2006). The Relationship Between Intragroup Conflict, Group Size and Work Effectiveness. Unpublished dissertation, BI Norwegian School of Management, Oslo, Norway. 
Hodgson, V., \& Reynolds, M. (2005). Consensus, difference and 'multiple communities' in networked learning. Studies in Higher Education, 30 (1), 11 - 24.

Huang, H. M. (2002). Toward constructivism for adult learners in online learning environments. British Journal of Educational Technology, 33(1), 27-37.

Jones, C., Connolly, M., Gear, A., \& Read, M. (2006). Collaborative Learning with Group Interactive Technology: A Case Study with Postgraduate Students. Management Learning, 37 (3), 377 - 396.

Johnson, D. W., \& Johnson, R. T. (2009). Energizing Learning: The Instructional Power of Conflict. Educational Researcher, 38 (1), 37-51.

Ke, F., \& Chellman, A.C. (2006). Solitary learner in online collaborative learning. A disappointing experience? The Quarterly Review of Distance Education, 7(3), 249265.

Kellogg, D. L., \& Smith, M. A. (2009). Student-to-Student Interaction Revisited: A Case Study of Working Adult Business Students in Online Courses. Decision Sciences Journal of Innovative Education, 7(2), 433-456.

Kahn, R., \& Kellner, D. (2007). Paulo Freire and Ivan Illich: Technology, Politics and the Reconstruction of Education. Policy Futures in Education, 5(4), 431-448.

Kollock, P. (1998). Social Dilemmas: The Anatomy of Cooperation. Annual Review of Sociology, 24, 183-214.

Kuhn, T., \&Poole, M. S. (2000). Do Conflict Management Styles Affect Group Decision Making? Human communication research, 26(4), 558-590.

Lankshear, C., Peters, M., \& Knobel, M. (1996). Critical pedagogy and cyberspace. In Henry A. Giroux, et al (Eds.) Counternarratives: Cultural Studies and Critical Pedagogies in Postmodern Spaces (pp.149 -189). NewYork: Routledge

Lindeman, E. (1926). The Meaning of Adult Education. New York: New Republic

Mantovani, G. (1994). Is computer-mediated communication intrinsically apt to enhance democracy in organizations? Human relations, 47(1), 45-62.

McConnell, D. (2005). Examining the Dynamics of Networked E-Learning Groups and Communities. Studies in Higher Education, 30 (1), 25-42.

McLaren, P., \& Jandrić P. (2015). The Critical Challenge of Networked Learning: Using Information Technologies in the Service of Humanity. In Jandrić and Boras (Eds.) Critical Learning in Digital Networks (pp. 199 - 226). Springer: New York

Morgan, C. J., Dingsdag, D., \& Saenger, H. (1998). Learning strategies for distance learners: Do they help? Distance Education, 19 (1), 142-156.

Parker, C. A. (2013). Peacebuilding Education: Using Conflict for Democratic and Inclusive Learning Opportunities for Diverse Students. International Journal of Peace Studies, 18 (2).

Paul, S., Seetharamanb, P., Samaraha, I., \& Mykytyna, P. P. (2004). Impact of Heterogeneity and Collaborative Conflict Management Style on the Performance of Synchronous Global Virtual Teams. Information \& Management, 41, 303-321.

Passos, A. M., \& Caetano, A. (2005). Exploring the effects of intragroup conflict and past performance feedback on team effectiveness. Journal of Managerial Psychology, 20, 231-244.

Picard, J. M. (April, 2006). Researching Social Conflict in Collaborative Groups. Networked Learning Conference. Paper presented at the Fifth International Conference on Networked Learning, Lancaster, UK.

Schwier, R. A. (2001). Catalysts, emphases, and elements of virtual learning communities. Implications for Research and Practice. The Quarterly Review of Distance Education, 2(1), 5-18. 
Smith, A. (1997). Problems of Conflict Management in Virtual Communities. In M. Smith, \& P. Kollock (Eds.) Communities in Cyberspace (pp. 135 - 165). London: Routledge Press

Smith, R. O. (2005). Working with Difference in online Collaborative Groups. Adult Education Quarterly, 55 (3), 182 -199.

Smith, R. O. (2008). The paradox of trust in online collaborative groups. Distance Education, 29 (3), 325-340.

Staggers, J., Garcia, S., \& Nagelhout, E. (2008). Teamwork through team building: face-to-face to online. Business Communication Quarterly, 71 (4), 472-487.

Stegmann, K., Weinberger, A., \& Fischer, F. (2007). Facilitating argumentative knowledge construction with computer-supported collaboration scripts. ComputerSupported Collaborative Learning, 2, 421 - 447.

Thomas, K. W. (1992). Conflict and conflict management: reflections and update. Journal of Organizational Behavior, 13, (3), 265-274.

Thomson, L., \& Ku, H. (2006). A case study of online collaborative learning. The Quarterly Review of Distance Education, 7(4), 361-375.

Usher, R. (1992). Experience in Adult Education: a postmodern critique. Journal of Philosophy of Education, 26 (2), 201-215.

Weinberger, A., Marttunen, M., Laurinen, L. \& Stegmann, K. (2013). Inducing sociocognitive conflict in Finnish and German groups of online learners by CSCL script. International Journal of Computer Supported Collaborative Learning, 8 (3), 333349.

Wenger, E. (1998). Communities of Practice. Learning, meaning and identity. Cambridge, U.K.; New York, N.Y: Cambridge University Press.

Whitworth, A. (2005). The politics of virtual learning environments: environmental change, conflict, and e-learning. British Journal of Educational Technology, 36 (4), 685-691.

Yates, S. (1997) Gender, identity and CMC. Journal of Computer Assisted Learning, 13, 281-90.

Xie, K., Miller, N. C., \& Allison, J. R. (2013). Toward a social conflict evolution model: Examining the adverse power of conflictual social interaction in online learning. Computers \& Education, 63, 404-415.

Zornoza, A., Ripoll, P., \& Peiro, J. M. (2002). Conflict Management in Groups that Work in Two Different Communication Contexts : Face-To-Face and ComputerMediated Communication. Small Group Research, 33, 481-508. 
Appendix 1: Coding scheme based on both the literature and data

\section{Conflict types}

a. Intrapersonal

- Interest: (Thompson and Ku, 2006) (a student member says in the pilot study) "They were just intending to pass this lesson, not to learn!"

- Wish: (Ayoko et al., 2002) (a student member says in the pilot study) "some people did not want to participate in. they thought that we would eventually finalize the project”.

- Ethnographic characteristics :(Ference and Vockell, 1994; Huang, 2002) Prior knowledge, prior experience. e.g. (a student member says in the pilot study) "my previous group work were always unfruitful, the other members did not contribute equally"

- Expectation: (the tutor says in the pilot study) "They (student members) complaint about their reporters and wanted me to change him/her. But we said it is not that important we only expect them to have a reporter who can put your decisions on internet”.

- Working preferences: (Ke and Chellman; 2006) (a student member says in the pilot study) "I can say that coming together with other members in the group was a big trouble for me"

b. Interpersonal

- Argument -Counterargument :(Stegmann et al.,2007) For instance, (a student member says in the pilot study)

"Tablet PC seems like a good idea, now, for example, a tutor teaches mathematics from here. if we also use microphone, there you go, it is a Smartclass." Another member replies: "But tutor says that it is very expensive, tablet PC is not possible, very expensive"

- Power relationships: (Blasé, 1991)- e.g. (a student member says in the pilot study) "I found out that they (other members) had hesitations on stating their thoughts to him (ambassador of the group)"

- Affiliation: e.g. (a student member says in the pilot study) "I did not feel belonging to the group"

\section{Internal dynamics of conflict}

Ontological security: (McConnell, 2005) e.g. (a student member says in the pilot study) "I did not trust them [the grop members- deadline causes anxiety]: when one week was left to the course, we could say we need to do this and that, you should do that, s/he should do that. We, a few people, came together and did something but we forcedly decided in whom to do what is next. But I cannot say this was useful."

- Learning culture: (Staggers et al, 2008) (Subject 4 says): "I am thinking that we had same goals and expectations while working with the group. [...] We took the advantage of learning from different points of view"

- Distribution of power

- Group size: (Kollock, 1998) (Subject 9 says) "But if we had been 3 people, that would have been more convenient to get the common points.”

- Technological factors: (Benbunan-Fich \& Hiltz, 1999): [emoticons] "To me, the only advantage of this implementation [she refers to online universities] is that it is nice to both work and study at the same time. Or I am very pessimistic as usual : $"$

\section{Potential results of conflict}

Conflict resolution- via

- Mediators: (Smith, 1997) (Subject 25 says): "I usually suggest some different ideas. I am a mediator when there is conflict. I also take the lead when necessary but this is not my preference."

- An authoritative figure: (Subject 10 says on Moodle under a thread titled 'task allocations` in the 4 week of the course) "Subject 13 informed [the tutor] that we have already chosen this topic" Tutor [in her email to that student]: "No, this topic belongs to the other group as they have chosen earlier than you and I have not heard anything from Subject 13 about that task allocation up to now"

- Dialogue: (Smith, 1997) (Subject 12)" On the times there was no consensus, we were discussing and took decisions together."

When conflict is unresolved

- Comply with conflict

a. Acceptance: (Subject 6 says): "[conflict in our group] could not be resolved and is left like that."

b. Oppression: (Whitworth, 2005) (Subject 17) says: " But I tried to disguise myself as if I was not leading"

- Fragmentations (Hodgson and Reynolds, 2005) (Subject 21 says) "While allocating the tasks, some different sub-groups emerged"

- Drop out 
Influence of conflict in learning

- Orientation: (Subject 10 says) "Because after some point, this reduces my motivation and I do not want to work as well”

- Knowledge production: (Subject 19 says) "Because in a group, there is more than one person, so, different point

of views is reflected on [our] presentation"

- Participation in co-operative and collaborative learning

- Chaos: Tutor says: "Student members confuse whom to listen, whom to follow." 
Appendix 2: Conflict-related characteristics of the students

\begin{tabular}{|c|c|c|c|}
\hline & & $\mathbf{N}$ & Total \\
\hline \multirow{2}{*}{$\begin{array}{l}\text { Learning } \\
\text { characteristics }\end{array}$} & $\begin{array}{l}\text { I am usually self motivated person } \\
\text { I am usually externally motivated person }\end{array}$ & $\begin{array}{c}21 \\
4\end{array}$ & 25 \\
\hline & $\begin{array}{l}\text { I usually look for a tutor or guidance in the courses to learn the subject } \\
\text { I usually prefer to work without any interference }\end{array}$ & $\begin{array}{l}11 \\
12\end{array}$ & 23 \\
\hline $\begin{array}{l}\text { Working } \\
\text { preferences: }\end{array}$ & $\begin{array}{l}\text { Working Individually } \\
\text { Working in Group } \\
\text { Both } \\
\text { Depends on (e.g. group members, course etc) }\end{array}$ & $\begin{array}{l}19 \\
3 \\
2 \\
7\end{array}$ & 31 \\
\hline $\begin{array}{l}\text { Role taking, } \\
\text { workload and } \\
\text { decision taking at } \\
\text { group work }\end{array}$ & $\begin{array}{l}\text { Role } \\
\text { I participate in equally } \\
\text { I take the lead } \\
\text { Depends ("if I like the topic I take significant responsibilities, otherwise, } \\
\text { I might not even participate in group work") } \\
\text { Workload } \\
\text { I work a lot } \\
\text { I pull my weight } \\
\text { Decision Taking } \\
\text { I accept what majority accepts } \\
\text { I take decisions together with other friends }\end{array}$ & $\begin{array}{c}16 \\
9\end{array}$ & 37 \\
\hline Prior knowledge & $\begin{array}{l}\text { I have some understanding } \\
\text { I have not explored this area } \\
\text { Very little } \\
\text { I have a strong understanding }\end{array}$ & $\begin{array}{l}18 \\
7 \\
2 \\
0\end{array}$ & 27 \\
\hline Expectation & $\begin{array}{l}\text { Method } \\
\text { Student centred education } \\
\text { Assignments should be given } \\
\text { Assignments should not be given } \\
\text { Project based education } \\
\text { Working with students from other universities } \\
\text { Learning by myself } \\
\text { Learning settings (LS) } \\
\text { Learning settings are important [these students do not specify what sort of LS they } \\
\text { expect to have] } \\
\text { Internet based } \\
\text { Other } \\
\text { Learn about subject matters } \\
\text { Enjoy } \\
\text { No comment }\end{array}$ & $\begin{array}{l}4 \\
3 \\
3 \\
1 \\
2 \\
1 \\
5\end{array}$ & 32 \\
\hline Aim & $\begin{array}{l}\text { Learn about distance education practices and theories } \\
\text { Pass with a good grade } \\
\text { Just to pass } \\
\text { Other (Enjoy, Improve my skills to work as a team, Participate in projects) }\end{array}$ & $\begin{array}{l}14 \\
7 \\
4 \\
5\end{array}$ & 30 \\
\hline
\end{tabular}

